\title{
LOS MONASTERIOS NACIDOS A TRAVÉS DE PACTOS EN LOS CONDA- DOS CATALANES DEL SIGLO IX. REFLEXIONES EN TORNO A LA PER- VIVENCIA DE UN MODELO FUNDACIONAL VISIGODO EN TIEMPOS DE LA REFORMA CAROLINGIA
}

\section{XAVIER COSTA BADIA}

\author{
UDC: $27-788$ \\ 27-523(460.23)"09" \\ Original scientific paper \\ Manuscript received: 31. 10. 2016. \\ Revised manuscript accepted: 27. 02. 2017. \\ DOI: 10.1484/J.HAM.5.113724
}

\author{
X. Costa Badia \\ Universitat de Barcelona \\ C/ Montalegre, 6 \\ o8ooı Barcelona, España \\ xaviercosta@ub.edu
}

\begin{abstract}
During the $9^{\text {th }}$ century, there was an important increase of monasteries in the Catalan counties. In few years, from 800 to 875, more than fifty new abbeys were founded; lots of them encouraged by the Carolingian authorities. Nevertheless, at the same time, some cloisters were established by founding pacts between their first monks and their abbot, without the intervention of any external power. In this article, I will study the survival of this pactual tradition, which was deeply connected to the Visigoth monasticism, during the Carolingian reform. The efforts made by their sovereigns in order to impose the Benedict's Rule were not enough to eradicate the previous monastic tradition, which remained in some of those early monasteries until the first years of the $10^{\text {th }}$ century.
\end{abstract}

Keywords: Early Middle Ages, Pactual monasticism, Carolingian reform, Catalan counties

En el noreste de la Península Ibérica, el monacato se documenta desde inicios del siglo IV y, a pesar de que en un primer momento no fue recibido con gran entusiasmo por las autoridades episcopales, acabó convirtiéndose en un fenómeno de gran relevancia política y social, alcanzando su período de máximo esplendor en época visigoda ${ }^{1}$.

Fue en ese momento, entre los siglos VI y VII, cuando el monacato hispano desarrolló sus manifestaciones más originales y empezó a tomar forma una verdadera red de cenobios. Sin embargo, aunque en las fuentes literarias y legislativas no faltan las menciones a monjes y abades², es difícil calibrar su presencia real sobre el territorio, ya que la documentación referente a monasterios concretos, exceptuando el caso de San Martín de Asán ${ }^{3}$ es prácticamente inexistente. Del mismo modo, la arqueología también se encuentra con muchas dificultades para poder identificar estos centros monásticos, cuya estructura no debía distar mucho de la de una villa laica $^{4}$, y, aunque la tendencia empieza a revertir ${ }^{5}$, son muy pocos los cenobios visigodos identificados y excavados. Esto no significa, en cualquier caso, que podamos dudar de su amplia implantación territorial a lo largo de este período.
No obstante, el próspero desarrollo del monacato hispano se vio interrumpido bruscamente en el siglo VIII por la invasión islámica de la Península. A priori, este suceso no tenía por qué suponer la desarticulación inmediata de la red monástica existente, ya que, como es bien sabido, la postura oficial del Islam respecto a los cristianos se basaba en la tolerancia a sus creencias, obligándoles únicamente al pago de dos impuestos extraordinarios ${ }^{6}$. Además, si nos centramos en la zona norte de la Tarraconense, el domino islámico fue realmente efímero y, por lo tanto, su incidencia social debió ser muy escasa ${ }^{7}$. Con todo, parece que cuando el poder franco consiguió superar los Pirineos y asentarse en su ladera meridional, todos los cenobios que habían poblado ese territorio se encontraban profundamente desorganizados.

En este sentido, cabe recordar que en las regiones que conformaban la Marca Hispánica es muy difícil atestiguar la pervivencia de algún monasterio visigodo en época carolingia, ya sea por medio de la documentación o de la arqueología. Sólo en el caso de Sant Sadurní de Tavèrnoles, y a pesar de los problemas que presentan sus primeros documentos,

\footnotetext{
${ }^{1}$ A.M. MUNDÓ, Il monachesimo nella Penisola Iberica fino al sec. VII. Questioni ideologiche e letterarie, in Il monachesimo nell'alto Medioevo e la formazione della civiltà occidentale, Spoleto, 1957, p. 73-117; P.C. DÍAZ, El legado del pasado: Reglas y monasterios visigodos y carolingios, in Monjes y monasterios hispanos en la Alta Edad Media, Aguilar de Campoo, 2006, p. 9-36.

2 J. CAMPOS, Juan de Biclaro, obispo de Gerona. Su vida y su obra, Madrid, 1960; J. VIVES, Concilios visigóticos e hispano-romanos, Barcelona-Madrid, 1963; J. CAMPOS, I. ROCA, San Leandro, San Isidoro y San Fructuoso. Reglas monásticas de la España visigoda. Los tres libros de las 'Sentencias', Madrid, 1971. Este listado no pretende ser exhaustivo; al contrario, es una mera muestra de las diferentes obras de carácter literario y normativo que nos permiten conocer el monacato visigodo y tardo-antiguo.

3 J. FORTACÍN, La donación del diácono Vicente al monasterio de Asán y su posterior testamento como obispo de Huesca en el siglo VI: Precisiones críticas para la fijación del texto, in Revista de Historia Jerónimo Zurita, 47-48, 1983, p. 7-70.

${ }^{4}$ L. CABALLERO, El conjunto monástico de Santa María del Melque (Toledo). Siglos VIII-IX (Criterios seguidos para identificar monasterios hispánicos tardo antiguos), in Monjes y monasterios hispanos en la Alta Edad Media, Aguilar de Campoo, 2006, p. 99-146.

${ }^{5}$ En relación a este cambio de tendencia, me gustaría reconocer los esfuerzos realizados por Marta Sancho, Jordina Sales y Laura de Castellet, que en este mismo volumen nos ofrecen nuevos datos sobre la identificación de posibles monasterios de época visigoda en el noreste peninsular.

${ }^{6}$ D. BRAMON, Moros, jueus i cristians en terra catalana. Memòria del nostre passat, Lleida, 2013, p. 39-41.

7 T.F. GLICK, From Muslim fortress to Christian castle: social and cultural change in medieval Spain, Manchester, 1995, p. 51-63.
} 
parece que puede intuirse cierta continuidad entre ambos periodos ${ }^{8}$. Además, entre las fuentes de principios del siglo IX, encontramos varias referencias a reedificaciones y refundaciones de monasterios ${ }^{9}$, terminología que no hace sino confirmar la presencia de una importante red monástica en el noreste peninsular visigodo y su desorganización durante los años de dominio islámico.

Las causas que provocaron esta situación son verdaderamente difíciles de percibir, sobre todo por la poca documentación conservada para el siglo VIII. Una de las explicaciones más aceptadas la ofreció Ramon d'Abadal, que consideró que los cenobios de los futuros condados catalanes pudieron haber sido destruidos por los musulmanes después del 778 como represalia por el intento fallido de Carlomagno de tomar Zaragoza ${ }^{10}$. No obstante, sin menoscabar esta posibilidad, creo que la simple pérdida del soporte político y social que seguramente acarreó la desaparición del poder visigodo y la islamización de las elites locales para mantener sus privilegios debió ser suficiente para poner en verdadero apuro los cenobios de estos territorios. Por otra parte, tampoco se puede descartar que, en realidad, fueran las propias autoridades francas las que promovieran la desarticulación del monacato visigodo, pues no olvidemos que en su intento de desvincular la Iglesia de la Marca Hispánica de la órbita toledana no dudaron en reorganizar completamente la sede visigoda de Urgell, deponiendo al obispo Félix bajo la acusación de adopcionismo y poniendo en su sitio a un sustituto afín a sus intereses ${ }^{11}$. En cualquier caso, no es éste el lugar para entrar a analizar a fondo las causas de la desorganización monástica que nos muestran las fuentes.

Es suficiente apuntar que esta discontinuidad en el desarrollo del monacato hispano propició que, después de la llegada de las tropas carolingias y la creación de los condados catalanes como marca frente a un temido contrataque musulmán, se produjera en este territorio lo que Ramon d'Abadal describió como un verdadero renacimiento monástico $^{12}$. Y no es para menos, ya que si a principios del siglo IX prácticamente no podemos acreditar la existencia de ningún monasterio en esta región, hacia el año 875, momento de formación de los primeros linajes condales autónomos, ya podemos documentar la presencia de más de cincuenta.

\section{LAS FUNDACIONES MONÁSTICAS DEL SIGLO IX, UNA APROXIMACIÓN HISTORIOGRÁFICA}

Evidentemente, a medida que se iba tomando conciencia del gran número de monasterios fundados en los condados catalanes a lo largo del siglo IX, también empezaron a aparecer las primeras hipótesis entorno a las causas que habrían provocado un fenómeno de tan alto alcance en un período tan corto de tiempo.

El primero en reflexionar profundamente sobre esta problemática fue el propio Ramon d'Abadal ${ }^{13}$. Éste se dio cuenta rápidamente de que, mientras que en los condados de Besalú, Girona, Empúries, Peralada y Rosselló parecía que habían predominado las fundaciones particulares llevadas a cabo por hispani, muchos de ellos regresados de la Septimania bajo la protección de Carlomagno, en las regiones más occidentales, léase los condados de Urgell, Pallars y Ribagorza, parecía que el peso de la restauración monástica había recaído sobre los obispos urgelitanos y, según matizó Manuel Riü ${ }^{14}$ los condes de Tolosa. Por lo tanto, a pesar de la existencia de algunas excepciones, Abadal concluyó que el auge monástico del siglo IX había tenido dos orígenes distintos según el territorio en el cual se había producido (fig. 1).

La tesis anterior, aceptada y seguida a posteriori por muchos otros autores ${ }^{15}$, se basaba rigurosamente en la documentación conservada. No en vano, disponemos de un gran número de preceptos de inmunidad relativos a los monasterios de los condados más orientales que especifican su creación por parte de hispani ${ }^{16}$, mientras que no hay ninguno para los que conformaban el antiguo obispado de Urgell. En cambio, para esta región existe un precepto de inmunidad del 823, el de Santa Maria de Senterada ${ }^{17}$, que, además de indicarnos que este cenobio había sido fundado por el obispo Posidonio de Urgell, nos informa que este prelado disponía de un privilegio de Luís el Piadoso que le autorizaba a fundar cuantos monasterios quisiera en los yermos del fisco. Este hecho, sumado a que en la temprana acta de consagración de Santa Maria de Urgell del 819 ya aparecen muchos de los cenobios de este territorio vinculados a la sede urgelitana ${ }^{18}$, todos bajo la advocación de Santa María, propició que Ramon d'Abadal y sus sucesores atribuyeran a la labor restructuradora de Posidonio de Urgell todos los

\footnotetext{
${ }^{8}$ M. RIU, Las comunidades religiosas del antiguo obispado de Urgel (siglos VI-XVI), Barcelona, 1960, p. 128 y 149-153; C. BARAUT, Diplomatari del monestir de Sant Sadurní de Tavèrnoles (segles IX-XIII), in Urgellia, 12, 1994-1995, p. 8-10.

${ }^{9}$ R. ABADAL, Els diplomes carolingis a Catalunya, Barcelona, 1926-1950, doc. 1 de Senterada, p. 259-262; ID., Els comtats de Pallars i Ribagorça, Barcelona, 1955, doc. 2, p. 281.

${ }^{10}$ R. ABADAL, El renaixement monàstic a Catalunya després de l'expulsió dels sarraïns, in Studia monastica, 3, 1, 1961, p. 167-168.

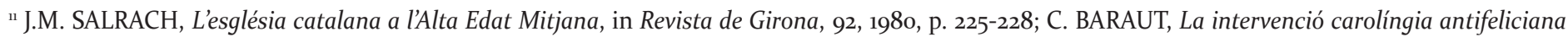
al bisbat d'Urgell i les seves conseqüències religioses i culturals (segles VIII-IX), in Jornades internacionals d'estudi sobre el bisbe Feliu d'Urgell. Crònica i estudis, La Seu d'Urgell, 2000, p. 155-193.

${ }^{12}$ R. ABADAL, op. cit. (n. 10), p. 165-177.

${ }^{13}$ ID., Els comtats de Pallars i Ribagorça, Barcelona, 1955, p. 203-207; ID., op. cit. (n. 10), p. 168-177.

${ }^{14}$ M. RIU, op. cit. (n. 8), p. 156-157.

${ }^{15}$ A. PLADEVALL, Els monestirs catalans, Barcelona, 1968, p. 32-34.

${ }^{16}$ R. ABADAL, Els diplomes carolingis a Catalunya, Barcelona, 1926-1950, doc. 1 de Albanyà, p. 5-8; Ibidem, doc. 2 de Arles, p. 24-26; Ibidem, doc. 1 de Banyoles, p. 45-47; Ibidem, doc. 1 de Fontclara, p. 113-115; Ibidem, doc. 1 de Sant Aniol d'Aguges, p. 176-178; Ibidem, doc. 1 de Sant Climent de Reglella, p. 180-182; Ibidem, doc.1 de Sant Genís les Fonts, p. 206-207; Ibidem, doc. 1 de Sant Julià del Mont, p. 219-221; Ibidem, doc. 1 de Sureda, p. $267-269$.

${ }^{17}$ Ibidem, doc. 1 de Senterada, p. 259-262.

${ }^{18}$ C. BARAUT, Les actes de consagracions d'esglésies del bisbat d'Urgell (segles IX-XII), in Urgellia, 1, 1978, doc. 2, p. 50-53; R. ORDEIG, Les dotalies de les esglésies de Catalunya (segles IX-XII), I. (Segles IX-X). Primera Part, Vic, 1993, doc. 1, p. 1-8.
} 


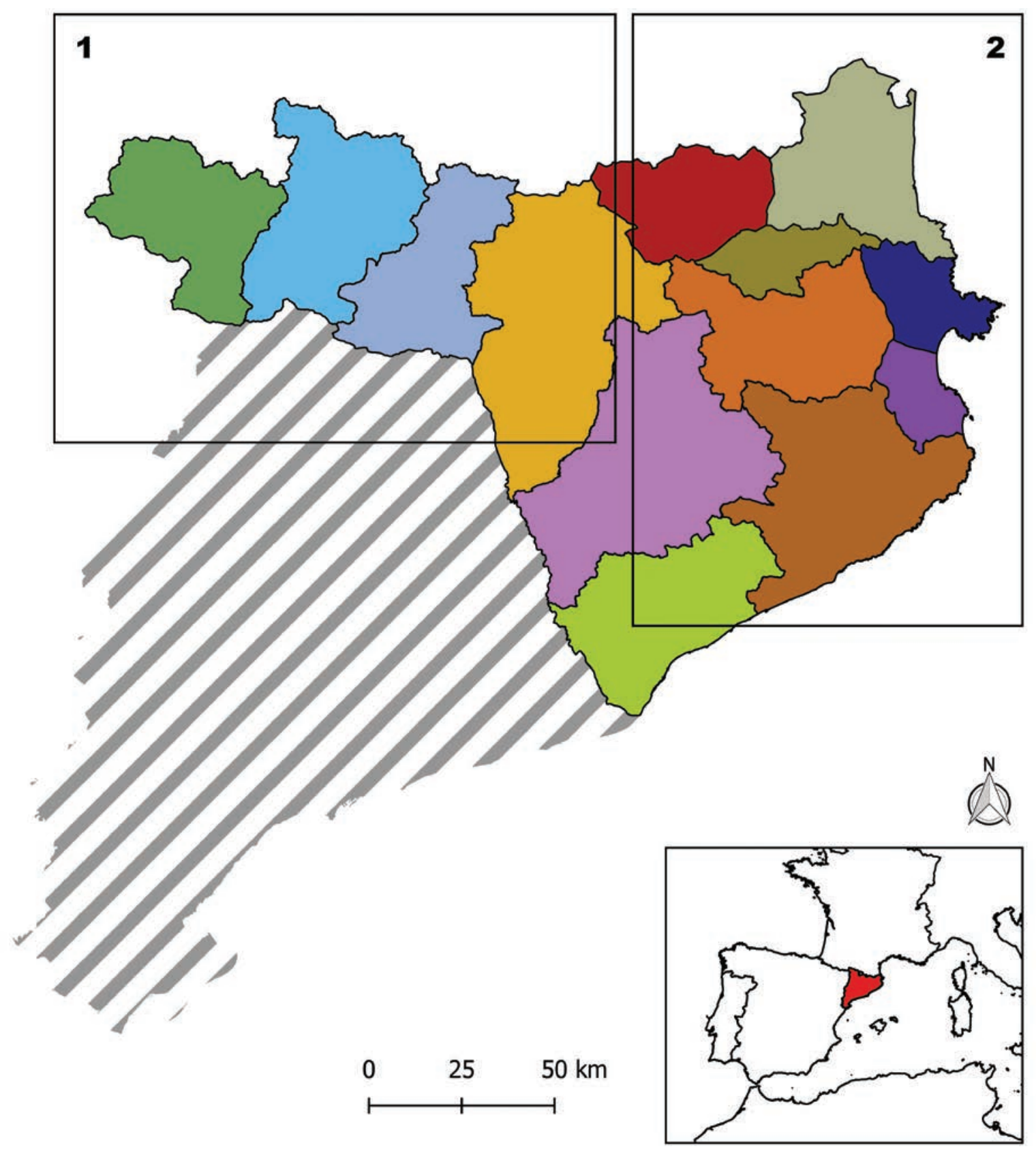

Fig. 1. División de los condados catalanes propuesta por Ramon d'Abadal según el origen de sus monasterios: fundaciones promovidas por las autoridades carolingias (1) o por hispani (2).

monasterios citados en ese documento; es decir, Senterada, Alaón, Taberna, Trempe, incluso, Vilanova y Ovarra, aunque estos últimos no sean mencionados directamente ${ }^{19}$.

Esta hipótesis, además, concordaba perfectamente con el contexto en que se encontraba el obispado de Urgell en aquellos momentos. Recordemos que, por orden de Carlomagno, desde el año 799, su último obispo visigodo,
Félix, se encontraba retenido en Lyon acusado de ser uno de los máximos difusores del adopcionismo, una herejía de carácter cristológico $^{20}$. Entretanto, se había encomendado la gestión de su diócesis a Leidrado de Lyon, Nefridio de Narbona y Benito de Aniano, todos ellos, y en especial el último, abanderados de la reforma general de la Iglesia que el poder franco había iniciado años atrás ${ }^{21}$. Por lo tanto,

${ }^{19}$ R. ABADAL, op. cit. (n. 13), p. 204-205; ID., op. cit. (n. 10), p. 168-169; A. PLADEVALL, op. cit. (n. 15), p. 32; C. BARAUT, El monestir de Sant Sadurní de Tavèrnoles i els orígens del monaquisme benedictí al comtat d'Urgell, in Studia monastica, 22, 2, 1980, p. 258-259. La inclusión de los monasterios de Vilanova-Lavaix y Ovarra entre los cenobios fundados por Posidonio de Urgell responde, básicamente, a su advocación mariana y a su evolución paralela a otros cenobios que sí aparecen en el acta del 819, como por ejemplo Alaón, cosa que permitió suponerles un origen parecido, hipótesis que en mi opinión debe ser revisada. Igualmente, también es discutible la atribución de un origen monástico a Santa Maria de Tremp, pues, aunque aparece mencionada en la citada acta junto a Senterada, no se ha conservado ningún otro documento que le atribuya esa condición.

${ }^{20}$ R. ABADAL, La batalla del adopcionismo en la desintegración de la Iglesia visigoda, Barcelona, 1949; M. RIU, Revisión del problema adopcionista en la diócesis de Urgel, in Anuario de Estudios Medievales, 1, 1964, p.77-96; J.C. CAVADINI, The Last Christology of the West: Adoptionism in Spain and Gaul (785820), Philadelphia, 1993; J. PERARNAU, Feliu d'Urgell: fonts per al seu estudi i bibliografía dels darrers seixanta anys, in Arxiu de Textos Catalans Antics, 16, 1997, p. 435-482; J. GIL, Aproximació a l'adopcionisme de Feliu d'Urgell, in Revista Catalana de Teologia, 29, 2004, p. 335-339.

${ }^{21}$ J.M. WALLACE-HADRILL, The frankish Church, Oxford, 1983, p. 258-303; J. SEMMLER, Réforme bénédictine et privilège impérial: Les monastères autour de saint Benoît d'Aniane, in Naissance et fonctionnement des réseaux monastiques et canoniaux, Saint-Étienne, 1991, p. 21-32. 

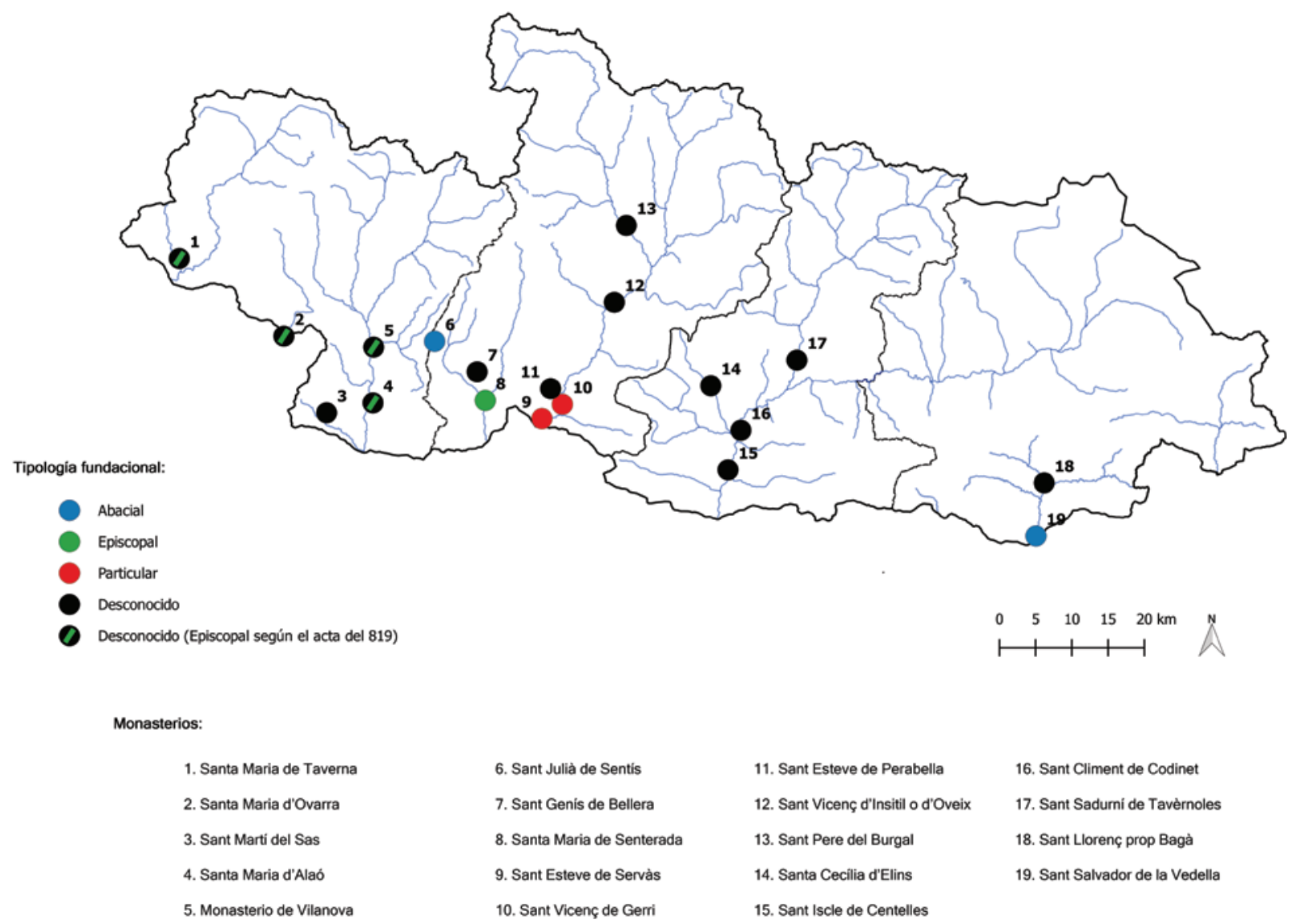

16. Sant Climent de Codinet

17. Sant Sadurni de Tavernoles

18. Sant Llorenç prop Bagà

19. Sant Salvador de la Vedella

Fig. 2. Monasterios del obispado de Urgell anteriores al 875 según su tipología fundacional

aunque no se había celebrado aún el concilio de Aquisgrán del 816 , donde la regla de San Benito se impondría como la única norma válida para los monasterios del Imperio, era fácil suponer que Benito de Aniana, durante su estancia en Urgell, ya habría empezado la reforma de los cenobios de aquel territorio, entre los cuales destacaría el de Tavèrnoles, potenciando que el sucesor de Félix, Posidonio, siguiera con esa labor reestructuradora bajo el signo benedictino ${ }^{22}$.

A lo largo de los años 8o y 9o, sin embargo, se empezó a poner en duda la veracidad del acta de consagración de Santa Maria de Urgell, hipótesis que hoy en día aceptan prácticamente todos los historiadores ${ }^{23}$. Este hecho altera notablemente todo lo que se creía saber sobre el monacato urgelitano del siglo IX y pone en entredicho la validez de la tesis expuesta anteriormente, ya que, sin tener en cuenta la citada acta, sólo la casa de Senterada se puede confirmar como una fundación de carácter episcopal. Sobre el origen de los otros veinte monasterios que tenemos documentados en la diócesis de Urgell en el siglo IX no sabemos nada, exceptuando, claro está, Sant Sadurní de Tavèrnoles, que sobre una primera fundación visigoda habría sido profundamente reformado por los missi enviados por Carlomagno en el
799; y los cenobios de Sant Vicenç de Gerri y Sant Esteve de Servàs, nacidos de manera autónoma mediante un pacto entre su abad fundador y sus primeros comunitarios (fig. 2).

En vista de estas novedades, como ya han apuntado algunos autores ${ }^{24}$, creo que podemos replantearnos en términos de continuidad o ruptura con el mundo visigodo el mal llamado "renacimiento monástico del siglo IX". Para hacerlo, precisamente creo que debemos centrarnos en los dos monasterios de fundación pactual antes citados; ejemplos que, después de haber sido considerados durante mucho tiempo como la excepción que confirmaba la regla, ahora se nos presentan con un interés renovado.

\section{GERRI Y SERVÀS, DOS MONASTERIOS DE TRADICIÓN PACTUAL}

Los cenobios de Sant Vicenç de Gerri y Sant Esteve de Servàs, situados en el condado de Pallars, son los dos únicos monasterios del ámbito catalán que han conservado el pacto fundacional que los originó ${ }^{25}$. Ambos, además, son de cronología similar, ya que uno es del 807 y el otro del 833 , apareciendo por lo tanto poco después de la conquista carolingia del territorio pallarés ${ }^{26}$.

\footnotetext{
${ }^{22}$ C. BARAUT, op. cit. (n. 19), p. 253-259.
}

${ }_{23}$ A. BENET, L'acta de consagració de l'església de la Seu d'Urgell. Un document fals, in Quaderns d'estudis medievals, 13, 1983, p. 137-143; C. BARAUT, La data de l'acta de consagració de la catedral carolíngia de la Seu d'Urgell, in Urgellia, 7, 1985, p. 515-529; M. RIU, La consagració del 819: Problemes sobre la seva autenticitat, in Catalunya Romànica, IX. L'Alt Urgell i Andorra, Barcelona, 1992, p. 318-320; R. ORDEIG, op. cit. (n. 18), p. 1-3; J. GARSABALL, Sobre la pretesa data de dotació de la Seu d'Urgell. Apunts per a una nova datació, in Analecta Sacra Tarraconensia, 67, 1994, p. 55-62; A. PLADEVALL, La documentació i l'art medieval, Barcelona, 1998, p. 21-33.

${ }^{24}$ J. C. BOIX, L'antic orde monàstic al comtat de Ribagorça, in Territori i Societat a l'Edat Mitjana, 3, 1999-2000, p. 115.

${ }^{25}$ R. ABADAL, op. cit. (n. 13), doc. 1, p. 280; Ibidem, doc. 9, p. 284-285.

${ }^{26}$ Ibidem, p. 89-91. La ocupación carolingia del valle de la Noguera Pallaresa, territorio que acabaría por conformar el condado de Pallars, parece que se produjo a finales del siglo VIII por iniciativa de los condes de Tolosa. Este hecho marcó profundamente su estatus dentro del Imperio, pues, sin negar en ningún caso el papel eminente del emperador, los condes tolosanos actuaron con gran libertad sobre estos territorios. Prueba de ello es que, cuando los preceptos de inmunidad aún acostumbraban a emanar de la cancillería imperial, en estos dominios ya eran emitidos por la autoridad condal. 
En forma y contenido, las semejanzas entre los dos pactos también son notorias, ya que ambos nos presentan a un presbítero, Espanell en el caso de Gerri y Salomón en el de Servàs, dando a sus "hermanos de fe" la fábrica monástica y ciertos bienes que servirían para dotar y garantizar la supervivencia de su fundación. Por su parte, suponemos que las respectivas comunidades les recompensarían jurándoles obediencia e invistiéndoles como abades de los cenobios recién fundados. Prueba de ello es que en el caso de Gerri, donde la documentación es mucho más abundante, tenemos una cesión del 817 en que Espanell ya aparece claramente citado como abad de la comunidad ${ }^{27}$.

Sin embargo, como he dicho, esta contraprestación sólo la podemos suponer, pues, a pesar de que estos documentos se autodefinen como pacti, únicamente contienen la donación unidireccional protagonizada por el abad. Este hecho ha permitido que algunos autores, entre los cuales destaca Antonio Linage Conde, les hayan negado la categoría de "pactos monásticos", restringiendo este concepto a los documentos en que se materializa un contrato bilateral con derechos y deberes mutuos entre las partes ${ }^{28}$. De este modo, además, se salvaguarda la tesis desarrollada por Charles J. Bishko, quien, sobre los planteamientos de Ildefons Herwegen $^{29}$, consideró que el pactismo era un rasgo diferencial del monacato galaico de época visigoda y que, en la Alta Edad Media, sólo se habría expandido por Castilla y la Rioja, en ningún caso Cataluña, debido a la participación de monjes de la Gallaecia en la repoblación de la frontera castellana ${ }^{30}$.

En una posición opuesta, se encuentran los historiadores que, siguiendo a Anscari Mundó ${ }^{31}$, consideran que el pactismo fue un rasgo común de todo el monacato visigodo y, en consecuencia, son proclives a aceptar como pactos monásticos de pleno derecho los ejemplos de Gerri y Servàs. Entre estos autores destaca Arcadi Garcia Sanz que, a partir de la definición de pactum y placitum contenida en diversas obras legales de época visigoda, razonó que un documento, para ser considerado jurídicamente un pacto, sólo debía contener un negocio jurídico entre dos o más partes, siendo innecesario que todas ellas contrajeran obligaciones y, menos aún, que hubiese condicionalidad recíproca entre las obligaciones de una y otra parte ${ }^{32}$. Por lo tanto, invalidaba uno de los principales argumentos esgrimidos contra los dos pactos estudiados.
Del mismo modo, Garcia Sanz se dio cuenta de que en la tradición visigoda toda la documentación era siempre unidireccional, siendo necesaria la redacción de dos diplomas distintos cuando se registraba un negocio jurídico bilateral33. En este sentido, si analizamos en profundidad todos los pactos monásticos conservados, veremos que, exceptuando algún caso tardío, incluso aquéllos considerados más perfectos por incluir limitaciones al poder del abad son en esencia actos unilaterales, ya que en realidad son los monjes los únicos que toman compromisos, aunque éstos estén condicionados al comportamiento del abad ${ }^{34}$. En base a esta tesis, parece lícito suponer que los pactos monásticos visigodos originariamente no se habrían compuesto de un solo documento, sobre todo cuando el abad también asumía obligaciones o cedía algún bien, sino de dos: uno expedido por él, dando a sus monjes sus posesiones; $y$ otro redactado por los comunitarios, reconociendo su autoridad. El problema es que no siempre se nos han conservado las dos partes del contrato y, en el caso de los pactos catalanes, a diferencia de la mayoría de los del noroeste peninsular, sólo se habría preservado la parte redactada por el abad fundador, posiblemente porque es la única que mantendría cierto valor como título de propiedad para el cenobio después de la muerte de éste.

Esta teoría, aunque no convenció a sus detractores ${ }^{35}$, me parece muy probable, sobre todo porque en el pacto de Sant Vicenç de Gerri el presbítero Espanell se refiere a sus compañeros como «fratribus meis in Christo qui dulcia carmina persolvitis et obediencia facitis aut promititis facere ${ }^{36}$, indicando claramente que con anterioridad o simultaneidad a su donación había recibido de ellos un juramento de obediencia. Igualmente, esta opinión se ve reforzada por la presencia, en las últimas líneas del pacto de Sant Esteve de Servàs ${ }^{37}$, de tres profesiones monásticas que podrían interpretarse como adnotationes in pactum; es decir, aquellas subscripciones que, según el Liber ordinum visigodo, los nuevos monjes debían imprimir sobre el pacto fundacional para hacerse partícipes de él y entrar a formar parte de la comunidad ${ }^{3}$. Por último, también respalda esta tesis el hecho de que ninguno de los dos documentos, a pesar de aparecer la palabra regula en el pacto de Gerri, precise que norma seguirían los monasterios fundados, rasgo más propio de la tradición visigoda, donde parece que había una regla ad hoc para cada cenobio ${ }^{39}$, que de la carolingia, donde se

\footnotetext{
${ }_{27}$ R. ABADAL, op. cit. (n. 13), doc. 3, p. 281-282.

${ }^{28}$ A. LINAGE, Los orígenes del monacato benedictino en la Península Ibérica, León, 1973, p. 300-304 y 325-335.

${ }^{29}$ I. HERWEGEN, Das Pactum des hl. Fruktuosus von Braga. Ein Beitrag zur Geschichte des suevisch-westgothischen Mönchtums und seines Rechtes, Stuttgart, 1907.

${ }^{30}$ C. J. BISHKO, Gallegan Pactual Monasticism in the Repopulation of Castile, in Estudios dedicados a Menéndez Pidal, II, Madrid, 1951, p. 513-531.

${ }^{31}$ A.M. MUNDÓ, op. cit. (n. 1), p. 104-106.

${ }^{32}$ A. GARCIA, Els pactes monàstics a la pre-Catalunya del segle IX, in Studia monastica, 16, 1, 1974, p. 8-11.

33 Ibidem, p. 11-13.

34 Ibidem, p. 19-25; R. LÉTINIER, Naturaleza jurídica y originalidad de los pactos monásticos, in El monacato en los reinos de León y Castilla (siglos VIIXIII), Ávila, 2007, p. 49-66.

${ }^{35}$ A. LINAGE, ¿Pactualismo en Cataluña?, in Yermo, 15, 1977, p. 45-60; C.J. BISHKO, The Pactual Tradition in Hispanic Monasticism, in Spanish and Portugese Monastic History 600-1300, London, 1984, p. 11-12; P.C. DÍAZ, op. cit. (n. 1), p. $23-24$.

${ }^{36}$ R. ABADAL, op. cit. (n. 13), doc. 1, p. 280.

37 Ibidem, doc. 9, p. 284-285.

${ }^{38} \mathrm{Ibidem}$, p. 216; A. GARCIA, op. cit. (n. 32), p. 33-42. El hecho de que no se haya conservado el documento original del pacto de Servàs, sino una copia del siglo XII, impide comprobar si realmente las traditiones identificadas como posibles adnotationes in pactum fueron añadidas a posteriori por una mano diferente. No obstante, creo que es una hipótesis muy sugerente que debe ser tenida en cuenta.

${ }^{39}$ A.M. MUNDÓ, op. cit. (n. 1), p. 93-97; I. VELÁZQUEZ, Reflexiones en torno a la formación de un «Corpvs Regvlarvm» de época visigoda, in Antigüedad y Cristianismo, 23, 2006, p. 531-567.
} 
potenciaba la existencia de una única regla, la de San Benito, como vemos claramente en el caso de Senterada, la única fundación de este momento indudablemente episcopal ${ }^{40}$.

En resumen, parece bastante claro que los monasterios de Sant Vicenç de Gerri y Sant Esteve de Servàs pueden vincularse directamente a la tradición pactista del monacato visigodo y no solamente a un viejo recuerdo de ésta. Por lo tanto, parece que, a pesar del interés de las autoridades carolingias por homogeneizar el monacato bajo el signo benedictino, habría algunos personajes de origen y cultura hispano-visigoda que seguirían fundado cenobios según las antiguas costumbres monásticas.

\section{¿CUÁL FUE EL PROCESO FUNDACIONAL SEGUIDO POR ESTOS MONASTERIOS?}

Aceptado el hecho de que en el caso de Gerri y Servàs no estaríamos ante fundaciones inspiradas por el poder carolingio, sino profundamente enraizadas en la tradición monástica anterior, debemos plantearnos cuál fue el proceso fundacional que precedió a la firma de los pactos analizados. Para hacerlo, ante la poca información disponible sobre estas dos abadías, debemos recurrir a otro monasterio de fundación particular no muy lejano, Sant Climent de Codinet.

El monasterio de Codinet, situado a escasos kilómetros al sur de la Seu d'Urgell, fue fundado el día 1 de enero del año 840 por medio de un documento que, más que un pacto, es una donación por la cual el presbítero Sentefredo, junto con otras tres personas, daba a la comunidad de Sant Climent el lugar de Codinet e «ipsa eglesia vel quantum ad ipsa eglesia pertinet» ${ }^{41}$. No obstante, lo especial de este caso es que contamos con tres documentos anteriores a esa fecha que nos muestran como, desde el año 815 , el presbítero Sentefredo venía comprando tierras en la zona donde se alzaría el futuro cenobio y, más interesante aún, iba recibiendo personas que se entregaban a él directamente bajo el título de «praesule nostro»; es decir, nuestro líder ${ }^{42}$. Por lo tanto, nos permite suponer que Sentefredo sería un personaje socialmente relevante, seguramente perteneciente a las elites locales hispano-visigodas, capaz por su prestigio personal de articular una verdadera comunidad monástica que, con el tiempo, él mismo dotaría con su patrimonio para que pudiese subsistir más allá de su muerte.

Este proceso fundacional creo que podría ser muy similar al vivido en Gerri y Servàs antes de la redacción de los pactos estudiados, aunque no disponemos de ningún documento que permita probarlo. El único argumento en contra de esta hipótesis es que en Codinet parece que nunca se tuvo la necesidad de firmar un pacto para constituir formalmente el monasterio, sino que se optó por una carta donationis que no permite intuir ningún juramento de obediencia por parte de los comunitarios. Esto, sin embargo, se podría deber a una temprana desvirtuación del sistema pactual, ya fuera por influencia de los postulados benedictinos ${ }^{43} \mathrm{o}$, simplemente, por un aumento de las diferencias socioeconómicas entre las partes contrayentes, cosa que habría hecho innecesario plasmar por escrito la sumisión de la comunidad a un personaje que, además de poseer patrimonialmente el cenobio, era ostensiblemente preeminente. En este último supuesto, la cesión de la fábrica monástica y sus bienes por parte del fundador no se habría producido en el momento de iniciar la vida en común, sino poco antes de su muerte, pues su objetivo no sería ser reconocido como abad, sino simplemente asegurar la pervivencia de su fundación, evitando que sus herederos pudieran ponerle fin.

Este planteamiento, aunque difícil de demostrar, concuerda perfectamente con lo que observamos en la documentación de Sant Climent de Codinet, puesto que, si en el año 815 ya era adulto, en el 840 Sentefredo tenía que encontrarse al final de su vida, como demuestra el hecho de que seis años más tarde otro abad dirigía su cenobio ${ }^{44}$. Del mismo modo, no me parece casual que la cesión del 840 apele repetidamente a los futuros abades del monasterio, característica poco habitual en las fuentes que da al texto un tono casi testamentario. En consecuencia, a pesar de no haber desembocado en la redacción de un pacto monástico, creo que el nacimiento de Codinet, igual que el de Gerri y Servàs, puede atribuirse a la iniciativa particular de un presbítero local, sin interferencias de ningún poder externo, siendo un ejemplo perfecto para aproximarnos a lo sucedido en esos dos cenobios antes de la firma de sus pactos fundacionales.

\section{¿HAY MÁS MONASTERIOS DE FUNDACIÓN PACTUAL?}

Una vez estudiados con precisión los pactos de Gerri y Servàs, así como el proceso que les precedió, debemos preguntarnos si estos monasterios son dos excepciones aisladas o si hubo otros cenobios que, a pesar de no haber conservado su pacto fundacional, también pudieron haber nacido bajo ese signo.

Dar respuesta a esta pregunta no es tarea fácil. No olvidemos que para la mayoría de los monasterios de los condados catalanes no disponemos de noticias sobre sus orígenes y, simplemente, cuando los encontramos documentados ya cuentan con una comunidad bien asentada. Sin embargo, a través de un análisis pormenorizado de las fuentes conservadas, podemos encontrar algunas evidencias que nos invitan

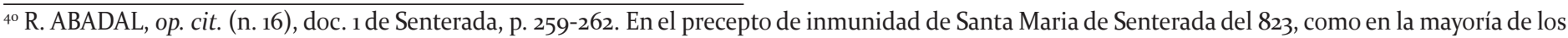
documentos imperiales de este tipo, se especifica claramente que en ese cenobio se debía observar la regla de San Benito.

${ }^{41}$ C. BARAUT, El monestir de Sant Andreu de Tresponts (segles IX-XVI), in Studia monastica, 26, 2, 1984, apéndice 2, doc. 1, p. 269-270. En este estudio sobre el vecino monasterio de Sant Andreu de Tresponts, Cebrià Baraut incluye algunos documentos de Sant Climent de Codinet que en su monografía sobre este cenobio del año 1982 no había podido localizar y, en consecuencia, publicar.

${ }^{42}$ C. BARAUT, Diplomatari del monestir de Sant Climent de Codinet (segle IX-XI), in Studia monastica, 24, 1, 1982, doc. 1-3, p. 158-161.

${ }^{43}$ Ibidem, p. 152-153. La Regla de San Benito parece que era conocida en Sant Climent de Codinet desde el momento de su fundación, ya que dos de los monjes que se entregaron a Sentefredo le prometieron stabilitatem, obedientiam et morum emendationem, los clásicos votos que esta norma prescribe. Sin embargo, en mi opinión, esto sólo demuestra que en aquel monasterio se concia esa regla, cosa normal teniendo en cuenta la visita de Benito de Aniano a la Seu d'Urgell en el 799, pero no que hubiese logrado ser aceptada como la norma única del cenobio. No olvidemos que en la praxis prebenedictina, donde cada monasterio conformaba su propia regla a partir de un corpus regularum más o menos amplio, era fácil aceptar e incorporar nuevos textos normativos sin repercutir sobre los preexistentes.

${ }_{44}$ Ibidem, doc. 5, p. 162-163.
} 
a sospechar que estaríamos ante un modelo fundacional más extendido de lo que se creía.

Uno de los primeros ejemplos que respalda esta hipótesis es el del monasterio de Vilanova, habitualmente identificado con Santa Maria de Lavaix. No en vano, el primer documento que lo menciona, referente a la fundación por parte de su abad Trasoario de un nuevo cenobio en el lugar de Sentís en el $848^{45}$, se autodefine como pactus, el mismo término que encontramos en el caso de Gerri. Este hecho pasó inadvertido a Ramon d'Abadal, que, ante el estilo barroco y casi ininteligible de su redacción, concluyó que lo único que se podía extraer de este documento era que el abad de Vilanova había establecido dos personajes, el presbítero Constantino y Atilano, en una iglesia fundada por él para que vivieran como monjes ${ }^{46}$. Sin embargo, Arcadi Garcia se dio cuenta que, en realidad, este complejo documento seguía de forma bastante precisa la estructura de los pactos monásticos tardíos, habituales en Castilla, donde se consigna en un mismo diploma la cesión del abad y la de la comunidad 47 .

Esta observación me parece muy interesante, ya que no sólo demuestra que Sant Julià de Sentís fue una fundación abacial realizada según la costumbre visigoda, sino que también permite inferir que en la casa madre seguían vigentes esos usos monásticos. No sería razonable pensar que el abad de un monasterio de tradición franco-benedictina hubiese recurrido a la liturgia hispano-visigoda para fundar una filial. Por lo tanto, creo que debemos desvincular el monasterio de Vilanova de las fundaciones inspiradas por el obispo Posidonio de Urgell y, aunque en su migrado archivo no hay ningún documento que permita confirmarlo, creo factible que en un primer momento hubiese seguido un proceso fundacional parecido al observado en Gerri y Servàs.

Del mismo modo, como en este caso sí apuntó Ramon d'Abadal, también podríamos suponer unos orígenes similares a Sant Andreu d'Eixalada, la pequeña casa que precedióal gran monasterio de Cuixà ${ }^{4}$. Esta tesis se basa en que, a pesar de no haberse conservado la carta fundacional del cenobio, cuando en el 854 profesaron allí el presbítero Protasio y sus compañeros, quienes lo dinamizarían notablemente, se redactó un extraño documento que, aunque hace referencia meramente a un arreglo económico, bien se podría interpretar como un pacto $^{49}$. A fin de cuentas, exponía que los nuevos comunitarios, al parecer con un importante poder adquisitivo, se comprometían a dar todos sus bienes al monasterio, en esos momentos bastante pobre, a cambio de preservar su usufructo mientras alguno de ellos siguiera con vida.

A favor de esta hipótesis aboga también el hecho de que, en el momento del traslado de la comunidad de Eixalada a Cuixà en el 879, cuando la regla de San Benito ya se había impuesto en el cenobio, todavía se redactó un documento fundacional que, si bien ya no se define como pactus y presenta un formulario bastante evolucionado, mantiene algunos elementos propios de la tradición anterior ${ }^{50}$. No olvidemos que, después de las firmas de los testigos, hay un gran número de adnotationes posteriores, hecho que demuestra que ese documento cumplía con las funciones de los antiguos pactos y que, durante cierto tiempo, siguió viva la práctica litúrgica visigoda de ir añadiendo la firma de los nuevos profesos al documento fundacional51. Así pues, creo que este cenobio también puede considerarse una fundación profundamente vinculada a la tradición pactual, manteniendo algunos de sus rasgos hasta bien entrado el siglo IX.

Por último, debo señalar que otros muchos monasterios, cuyos orígenes no podemos conocer por falta de fuentes, podrían vincularse con fundaciones hechas por particulares al margen de la intervención del poder carolingio. En este sentido, me gustaría plantear la posibilidad que incluso el monasterio de Alaón, la gran abadía ribagorzana, tuviera un origen enraizado en la tradición visigoda, ya que, a pesar de recibir entre el 806 y el 814 un precepto del conde Bigón de Tolosa que autorizaba su fundación por parte del presbítero Crisógono ${ }^{52}$, no sabemos nada sobre este personaje y el modelo que siguió para refundar esa casa. Además, me parece muy curioso que, con un fondo documental tan extenso como el suyo, tengamos que esperar hasta el año 954 para encontrar una mención clara a la regla de San Benito53; omisión que, teniendo en cuenta que este tipo de referencias no serán extrañas a partir de ese momento ${ }^{54}$, podría indicar una aceptación bastante tardía de la norma promovida por el poder franco.

A la luz de las pruebas presentadas, creo que hay argumentos suficientes para afirmar que los casos de Gerri y Servàs, donde la iniciativa fundacional recayó exclusivamente sobre los primeros miembros de la comunidad, sin ninguna injerencia externa, no pueden ser considerados excepcionales. Al contrario, entiendo que es un modelo fundacional muy sugerente que, habida cuenta de la gran cantidad de referencias a abades fundadores contenidas en los preceptos imperiales y de las muchas pervivencias del mundo visigodo que observamos en los primeros cenobios del siglo IX, podría ser extrapolado a otros monasterios del territorio catalán, aunque esta hipótesis es muy difícil de demostrar por la falta de documentación conservada.

\section{CONCLUSIONES}

En definitiva, podemos concluir que, si obviamos los documentos que la crítica diplomática ha demostrado falsos y

\footnotetext{
45 R. ABADAL, op. cit. (n. 13), doc. 39, p. 302-303.

${ }^{46}$ Ibidem, p. 239.

${ }^{47}$ A. GARCIA, op. cit. (n. 32), p. 27-29. El documento, según la interpretación de Arcadi Garcia, empieza con la donación unilateral de la iglesia de Sant Julià de Sentís por parte de Trasoario, cesión que está redactada en primera persona del singular. No obstante, acto seguido, e introducido por un simple "ideo", se produce el pacto de obediencia de Constantino y Atilano, redactado en primera persona del plural. Finalmente, y después de un nuevo “ideo", Trasoario vuelve a tomar la palabra y, en singular, concluye su pacto dándoles libertad para elegir, después de su muerte, el abad que decidan.

${ }^{48}$ R. ABADAL, Com neix i com creix un gran monestir pirinenc abans de l'any mil: Eixalada-Cuixà, in Analecta montserratensia, 8, 1954-1955, p. 126-127 y 130-134.

49 Ibidem, apéndice 1, doc. 9, p. 250-252; A. GARCIA, op. cit. (n. 32), p. 18.

5o Ibidem, apéndice 1, doc. 61, p. 280-282.

${ }^{51}$ A. GARCIA, op. cit. (n. 32), p. 30-31.

${ }^{2}$ R. ABADAL, op. cit. (n. 13), doc. 2, p. 281.

53 Ibidem, doc. 163 , p. 368-369.

54 Ibidem, doc. 165, p. 369-370; Ibidem, doc. 170, p. 373; Ibidem, doc. 209, p. 394-396.
} 
ponemos en valor los hasta ahora menospreciados pactos de Gerri y Servàs, podemos replantearnos de manera notable como se fundaron muchos de los cenobios nacidos en los condados catalanes a lo largo del siglo IX.

Evidentemente, no se pretende negar el papel importantísimo que jugó el poder carolingio en este proceso de restructuración del monacato. Los numerosos preceptos de inmunidad conservados, junto con la venida del mismo Benito de Aniano a Urgell, dan cuenta del interés de estos gobernantes para fundar, reformar y atraerse los cenobios de la Marca Hispánica. Sin embargo, sí se quiere destacar que, al lado de los monasterios promovidos por las autoridades francas bajo el signo benedictino, parece que hubo otras fundaciones, posiblemente más de las que se creía, sobretodo en el obispado de Urgell, nacidas por un proceso endógeno y que acabaron tomando personalidad jurídica por medio de un pacto fundacional entre su primer abad y sus primeros monjes.

Así pues, creo que debemos prescindir de la vieja distinción entre unos condados orientales donde las fundaciones corrieron mayoritariamente a cargo de los hispani autóctonos y unos condados occidentales donde llevaban la iniciativa los condes y obispos carolingios. En mi opinión, en ambos territorios debió sobrevivir al dominio islámico un importante sustrato monástico que, si bien podía encontrarse profundamente desorganizado, permitió la aparición de unos presbíteros capaces, por su prestigio social y religioso, de articular y cohesionar unas incipientes comunidades a su alrededor. Serian estos personajes, probablemente pertenecientes a las elites locales, los que, con la llegada de un nuevo poder político cristiano, habrían decidido refundar algunas casas preexistentes o crear otras ex novo, siempre siguiendo los ritos y costumbres que les eran propios, los del mundo hispano-visigodo.

En cualquier caso, no hay duda que, con el tiempo, estos cenobios también establecieron importantes relaciones con el poder carolingio. En este proceso, pudo jugar un papel importante su ubicación geográfica, ya que normalmente los monasterios del siglo IX se ubicaron en el centro de territorios con gran coherencia interna, cosa que, a los ojos de las autoridades francas, les debía convertir en unidades estratégicamente muy importantes para ayudarles a controlar y reestructurar esos pagi y territoria ${ }^{55}$. Así pues, vemos como muy rápidamente empezaron los contactos con esas autoridades y, sin ir más lejos, Vilanova y Gerri, dos de los cenobios de tradición pactual más claros, ya recibieron un precepto de inmunidad del conde de Tolosa en el año $849^{56}$.

Este inevitable acercamiento al poder carolingio, sin duda, tubo que acarrear profundas transformaciones en la vida interna de estos monasterios, pues la intención de los gobernantes francos siempre fue homogeneizar el monacato de sus dominios según el modelo benedictino. Prueba de ello es que los privilegios de inmunidad expedidos por la cancillería imperial, en la mayoría de los casos, conllevaban la aceptación de la regla de San Benito. En consecuencia, a pesar de que se detectan algunas reservas en la aceptación de esa norma, la voluntad reformista de las autoridades carolingias provocó que muchas de las tradiciones del monacato visigodo se fueran gradualmente difuminando hasta desaparecer definitivamente ya entrado el siglo X.

55 J. BOLÒS, El monestir com a institució feudal, in Temps de monestirs: Els monestirs catalans entorn l'any mil, Barcelona, 1999, p. 70-73.

${ }_{56}^{6}$ R. ABADAL, op. cit. (n. 13), doc. 40 y 41, p. 303-305; ID., Els preceptes comtals carolingis per al Pallars, in Butlletí de la Reial Acadèmia de Bones Lletres de Barcelona, 26, 1956, p. 11-60.

"Este artículo se inscribe dentro del proyecto "Paisajes espirituales", financiado por el Ministerio de Economía, Industria y Competitividad del Gobierno de España (MINECO HAR2014-52198P). 